\title{
Aspect and Aktionsart: A Study on the Nature of Grammatical Categories:
}

\author{
Amalia Moser \\ University of Athens \\ amoser@phil.uoa.gr
}

\section{Abstract}

The topic of this paper seems perhaps over-ambitious, touching as it does on several questions which have become serious theoretical issues over the last decades and some of them over several centuries. The controversy on the nature of grammatical categories has marked Philosophy and Linguistics throughout the twentieth century; the more modest controversy on aspect and its relationship to the disputed category Aktionsart, as well as its relationship to tense, has been dealt with in a vast amount of literature.

This short paper cannot provide a definitive answer; it has the more modest aim of showing

a) that Greek aspect and Aktionsart form a continuum

b) that the two categories remain nevertheless distinct

and thus hopefully contribute to the broader discussion on gradience, in particular intersective gradience, as defined by Aarts (2007).

\section{The Discreteness of Categories}

Aristotle, with his clarity of thought and passion for precision, shaped the way in which the concept of category was almost uniquely understood until the 20th century: a category is defined by the necessary and sufficient conditions which determine, unequivocally, whether each entity belongs or not to the category; tertium non datur. Classical Logic never digressed from this principle, even though there were some dissenting voices even in Antiquity. ${ }^{1}$

\footnotetext{
*My warmest thanks to the organising committee for inviting me to present this paper, to the linguists in the audience for their stimulating questions and comments, to the anonymous reviewers and to all the other colleagues and students who have provided me with thoughtprovoking material, especially the objections which led to the fuller development of the theoretical arguments put forward in this paper.

1 Eubulides of Miletus, from the school of Euclides of Megara, with his sorites paradox, is the best-known example (cf. e.g. Aarts et al. 2004: 2).
}

\section{(cc) BY-NC-ND}


These voices were few and far apart because at first sight (that is, for the first twenty-four centuries or so) this concept seemed to function perfectly well for natural classes, especially for the taxonomy of plants and animals. The biological hierarchy kingdom > class > order > genus > species > variety (as systematized by Linnaeus in the $18^{\text {th }}$ century and with a few later amendments shown in Figure 1) took excellent care of the natural world. To take an example, the phylum of vertebrates was subdivided into classes, with the possibility of intermediate superclasses (Figure 2):

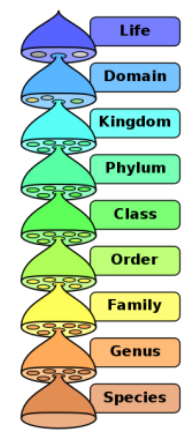

Figure 1. Biological Classification²

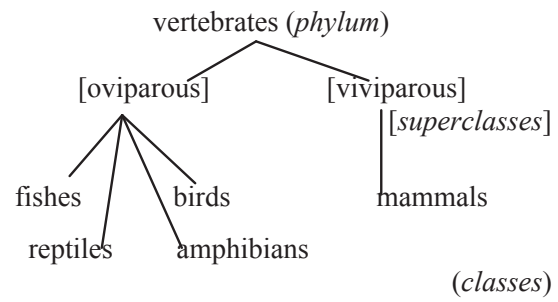

Figure 2. Traditional classes of vertebrates

In the $19^{\text {th }}$ century, however, new data started coming in. The discovery of Australia, for instance, brought along the discovery of animals such as the platypus, which is at the same time a mammal and an egg-laying animal, a fact also mirrored in its appearance, as it is both furry and beaked.

2 Peter Halasz, based on Carl R. Woese, Otto Kandler, Mark L. Wheelis (1990) Towards a natural system of organisms: proposal for the domains Archaea, Bacteria, and Eucarya. Proceedings of the National Academy of Sciences of the United States of America 87: 4576-4579 ( the article in which the level of 'domain' is proposed). The representation was downloaded from Wikipedia (http://en. wikipedia.org/wiki/File:Biological_classification_L_Pengo_vflip.svg ). 
Several other findings, such as that vertebrates are closely related to nonvertebrate but craniated species, as well as non-craniated animals, led to the postulation of several intermediate categories, on which, incidentally, there is no absolute consensus among biologists: a superphylum of deuterostomia and a phylum of chordates, which includes vertebrates among other subphylums (tunicata, cephalochordata). The platypus and the echidna had to be accommodated into a sub-class of their own, thus seriously upsetting the symmetry of the model:

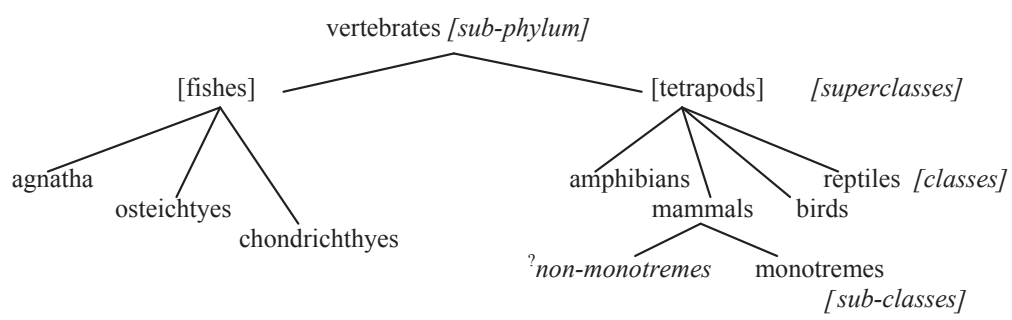

Figure 3. Categorization of vertebrates

Ironically, therefore, it was progress in the natural sciences, the major supporters of classical categorization, that created the most serious rifts in the conception of categories. It showed that, rather than being discrete and clearly defined, even natural categories could be vague. The vigorous philosophical discussions that this development generated led to the theory of prototypes; Tsohatzidis (1990: 1 ) provides one of the most succinct and lucid descriptions in the literature:

[...] elements are assigned to a category not because they exemplify properties that are absolutely required of each one of its members, but because they exhibit to a greater or lesser extent [...] certain types of similarity with a particular category member that has been (naturally or culturally) established as the best example (or prototype) of its kind.

Later developments led to definitions allowing for the possibility of the prototype being an abstraction based on (the attributes of) a number of focal members of a category; in the words of Jaszczolt (2002: 34) "the core prototype can be regarded as a real example or an abstract set of characteristic features".

Currently in Linguistics both approaches find equally staunch supporters, with the two main theories of language, generative and cognitive, respectively adopting discreteness and vagueness or fuzziness. 
The position adopted here is halfway between the two. It is maintained that the perception of category membership, and by extension of categories, is prototypical; both the relevant philosophical arguments and the psychological experiments (even the earliest ones, e.g. Rosch 1973, 1978) seem conclusive. Nevertheless, the extreme position of many advocates of gradience that there is no possibility of defining even prototypical members in a strict manner is not adhered to - instead, it is proposed that it is not only possible but desirable to define prototypical members in as rigid a way as possible; this would be compatible with the ease with which they are recognized. Paradoxically, perhaps, both of these convictions, which seem contradictory, stem from the same beliefs about the properties of the human mind. As Saussure and classical Structuralism have shown, categories are not imposed by reality, but are the result of our own decisions, within our attempt to put some order to the world around us. Not having a clear idea of at least the prototypical members of these categories would defeat the purpose of postulating them.

From the 1980s onwards there has been a growing tendency to attribute prototypicality to grammatical categories. The seminal article by Hopper \& Thompson (1984) on "The discourse basis for lexical categories in Universal Grammar" was particularly influential; 3 it was followed by Taylor's 1989 book on Linguistic Categorization, while most major cognitive works attribute fuzziness and prototypicality to basic grammatical notions, such as those of word, phoneme, verb, noun, adjective etc., often using for them the term 'radial categories'.

A belief in prototypicality leads naturally to a belief in the existence of continua. The fuzziness of categories, providing as it does for different degrees of membership as well as for membership of multiple categories, allows chains of entities linking different categories. Again, however, the view adopted here is that, if continua are to make any sense, their end points should be rigidly defined, even in cases where there are no clear instances of them in actual fact. This conviction is best expressed in Aarts (2007: 201):

If it is claimed that there is gradience between two categories $\alpha$ and $\beta$, then it must first be established that $\alpha$ and $\beta$ actually exist as word classes. In other words, the well-motivated setting up of discrete categories of form classes is logically prior to claiming that gradience obtains between them. Paradoxically, adherents of gradience models must face the fact that their analytical point of departure should always be rigid discreteness.

3 In Moser (1988), e.g., the category perfect as well as auxiliary verb and periphrasis are analysed on the basis of prototypicality. 
The term 'gradience', introduced by Bolinger (1961), has been gaining ground in the last few years, affording a terminological expression of the logical connection between prototypes and continua. Aarts distinguishes two types of gradience, subsective and intersective. The former is "an intra-categorial phenomenon which allows members of a class to display the properties of that class to varying degrees" (Aarts 2007: 79). Intra-categorial gradience leads to prototype effects. ${ }^{4}$ Intersective gradience, by contrast, is "an inter-categorial phenomenon which comes about when two form classes 'converge' on each other" (ibid.). Continua belong to this second type of gradience.

\section{Time in Language}

Tense, aspect and Aktionsart all have to do with time. Time is a very important concept for humans, not only in recent years, when it has become a valuable commodity, to be measured, allotted with precision to different tasks and priced accordingly, but throughout human history. It is important, however, to stress that it is a CONCEPT. There is no concrete physical entity to which it corresponds, such as there is for the concept of space, for instance. It is a construct of the human mind. ${ }^{5}$

There are two sources of our understanding of time:

The most obvious one is human life and its inevitable progression from birth to death. This gives us our basic linear concept of time: we usually perceive it

\footnotetext{
4 The term 'prototype effects' is used here to imply that subsective gradience is not necessarily equated with prototypicality. In fact, Aarts (2007: 87-90) insists on distinguishing the two, on the grounds that gradience is predominantly a grammatical phenomenon, while prototypicality concerns conceptual entities in general, has an almost exclusively semantic basis and does not necessarily apply to linguistic entities; for one thing, the prototypicality criteria for the latter would be completely different to the concrete criteria applied to physical objects (shape, colour etc.). My own view is that prototype effects work in exactly the same way in both cases, hence it is entirely justified to speak of prototypicality in grammatical categories; much is made of the different type of criteria in the literature, but this difference seems immaterial, especially if the case of abstract entities is taken into account. Moreover, even though grammatical categories are the product of linguistic theorizing, it is probably fair to say that the process of categorization must be the same as in the case of physical entities. The point, nevertheless, need not be argued any further, since subsective gradience is not the object of this paper. 5 According to modern Physics, and specifically Albert Einstein's and Stephen Hawking's theories, time as a physical entity apparently has not much to do with time as we conceive of it, being one of the four dimensions and, if I understand correctly (mainly on the basis of Jaszczolt 2007), static. Movement, however, is a crucial feature of what we understand as time. This is verified by the existence in most languages of expressions such as "the flow of time".
} 
as a line with the present at its center extending infinitely towards the past and the future.

The linear conception of time is usually represented as shown in Figure 4 (following the convention of left-to-right reading):

$\longleftarrow$ past $\quad$ present $\quad$ future $\rightarrow$

Figure 4. The Time Axis

A less obvious but more primitive source for our concept of time is the regular repetition of certain phenomena (the cycles of day and night, the succession of seasons etc.) We become aware of these long before we become aware of life and death, and they give us a sense of time moving in circles, repeated at regular intervals. This cyclical perception is reinforced by our sense of rhythm, which has its source in our earliest experiences: hearing our mother's heartbeat and later feeling our own.

All languages express time in their vocabulary and very many through their grammar, most commonly the verb. Grammatical expression usually involves the linear concept of time. There is some debate as to whether there might not be languages, in particular Australian ones, which reflect exclusively the cyclical conception of time (cf. e.g. Comrie 1985: 4-5); this is rather doubtful, since the cycles also proceed in a linear sequence. Most languages display both concepts, since both are equally essential in our experience of the world, even if linearity prevails in grammatical systems.

\subsection{Tense}

Tense is the grammatical category expressing the location of events on the axis of time. Events are located along the line shown in Figure 4, usually in respect to the present, which of course is the present of the speaker. This means two things:

a) that we perceive time in more or less locational terms; in other words we have imagined time as space, and have thus created a metaphor based on space

b) that we perceive it deictically, in egocentric terms.

Nevertheless, the term absolute tense is used when the point of reference is the present (i.e. the 'now' of the speaker); the term relative is reserved for time defined in respect to another event. The term absolute-relative tense is used when this second event is placed in respect to the speaker's present.

The somewhat controversial analysis of the Modern Greek tense system in Moser (1994, 2009) concludes that morphologically Modern Greek expresses 
past, present and future, as well as anteriority in all three time spheres, as shown in Table 1 below. $^{6}$

Table 1.

Tense in the Greek Verb

\begin{tabular}{|c|c|c|c|}
\hline & tense $^{\text {aspect }}$ & [+ PERFECTIVE] & [-PERFECTIVE] \\
\hline \multirow{3}{*}{ 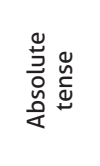 } & past & 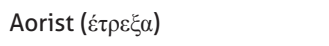 & Present $(\tau \rho \varepsilon ́ \chi \omega)$ \\
\hline & present & - & 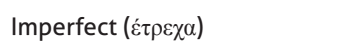 \\
\hline & future & 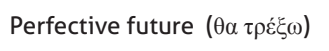 & Imperfective future $(\theta \alpha \tau \rho \varepsilon ́ \chi \omega)$ \\
\hline \multirow{3}{*}{ 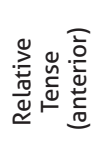 } & past & 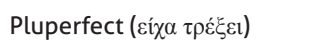 & - \\
\hline & present & Present Perfect ( $\dot{\varepsilon} \chi \omega \tau \rho \varepsilon \dot{\xi} \xi \varepsilon)$ & - \\
\hline & future & 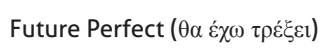 & - \\
\hline
\end{tabular}

The relationship of tense and aspect has been a subject of controversy; an association of the perfective with the past tense has often been pointed out (notably in Bybee, Perkins \& Pagliuca 1994). The most obvious candidate for contributing to a gradient is the perfect, given the ongoing debate about whether it is a tense or an aspect. The relationship of tense and aspect in Greek has been explored in interesting ways in several recent works, notably by Xydopoulos \& Tsangalidis (2007). The table above shows that the association of the perfective with the past is not an issue for Greek, while the (admittedly controversial) analysis of the perfect adopted here places it firmly in the category of tense. Under this analysis, then, the only indication of an interaction of the two categories lies in the absence of a perfective form for the (absolute) present ${ }^{7}$ and of an imperfective form for any of the anterior tenses. ${ }^{8}$ None of these issues will be addressed here; the table, however, can be used as an overview of the entire tense and aspect system.

6 This table leaves out the very interesting non-temporal uses of the tenses, which are outside the scope of this paper. Several studies of individual tenses are available; for a comprehensive analysis see Bella 2005.

7 In several analyses (e.g. Holton et al. 1997) the form $\tau \rho \varepsilon \xi_{\omega} \omega$ is dealt with as a perfective present, even though it is not used as an independent form.

$\mathbf{8}$ While the form of the (main) verb used for the formation of the perfect is unquestionably perfective, there is no consensus about the perfect's aspectuality. It has been analysed as perfective (the view adopted here), as a third aspect (both these analyses are given as alternatives in Clairis \& Babiniotis 2005) and even as imperfective, because of the imperfectivity of the auxiliary (Tsangalidis 1999). 


\subsection{Internal Temporal Constituency}

Aspect and Aktionsart are both perceived as being associated with the internal temporal constituency of situations.

\subsubsection{Aktionsart}

Regardless of their position on the time axis, situations occupy a point or a space on it, i.e. a chunk of time. Hence, they can be:

- durative (whether long- or short-lasting) or instantaneous cf. a situation like searching vs. finding

- continuous or intermittent cf. the continuous ringing of a bell vs. a bell that rings every five seconds

- homogeneous or consisting of clearly discernible phases cf. walking on a treadmill for exercise vs. walking from the station to a hotel

- including an end point or open-ended cf. baking a batch of cookies vs. being a baker by profession

These distinctions were pointed out long ago, starting in fact with Aristotle. During the last century there have been several attempts to categorize them systematically, mostly amongst philosophers. The most widespread categorization is the one by Vendler (1957) into states, activities, accomplishments and achievements, based on the criteria of telicity (i.e. the inclusion of an end point) and divisibility into phases. The latter is particularly important for English, because of the nature of its aspectual system, but it is applicable crosslinguistically.

Table 2.

Vendler's categorization

\begin{tabular}{|c|c|c|}
\hline & [-PHASES] & [+PHASES] \\
\hline \multirow[b]{2}{*}{ [-TELIC] } & STATES & ACTIVITIES \\
\hline & $\begin{array}{l}\text { sleep } \\
\text { love } \\
\text { be alive }\end{array}$ & $\begin{array}{l}\text { run } \\
\text { paint } \\
\text { search }\end{array}$ \\
\hline \multirow[b]{2}{*}{ [+TELIC] } & ACHIEVEMENTS & ACCOMPLISHMENTS \\
\hline & $\begin{array}{l}\text { die } \\
\text { find } \\
\text { recognize }\end{array}$ & $\begin{array}{l}\text { run a mile } \\
\text { paint a portrait } \\
\text { read a book }\end{array}$ \\
\hline
\end{tabular}

The categorization by Mourelatos (Figure 5), while hierarchical, ends up with the same four categories (see the corresponding terms in brackets). 


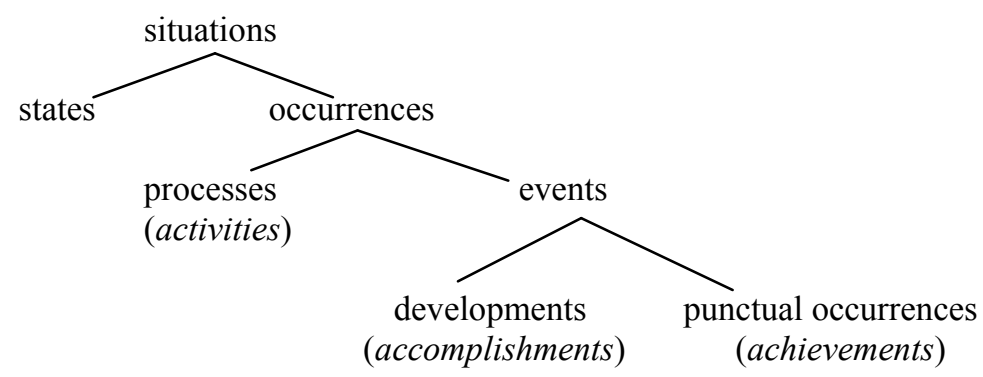

Figure 5. Mourelatos' categorization

Sasse (1991) includes a fifth category (inchoative statives) consisting of verbs like love, know etc., which double as statives and inchoatives

(1) I love Thessaloniki

(2) I loved Thessaloniki instantly

Although such verbs have a rather special position in Greek and provide interesting information, especially for the history of aspect, in terms of internal temporal constituency they are covered by the other categorizations mentioned, since their two meanings/uses fall under states and achievements respectively.

It should be mentioned at this point that there are serious objections in the literature not so much to the specific categorizations as to the category of Aktionsart itself as distinct from aspect, which will be discussed briefly after the description of the latter.

\subsubsection{Aspect}

The existence of a grammatical category "aspect" is not in dispute, even though it only entered Western European grammars in the 1840 s via Slavic Grammar. Comrie's (1976: 3) classic definition is more or less universally accepted:

Aspects are different ways of viewing the internal temporal constituency of a situation.

This is further elaborated in his definition of the subdivisions of the category, perfective and imperfective:

"Another way of explaining the difference between perfective and imperfective meaning is to say that the perfective looks at the situation from outside, without necessarily distinguishing any of the 
internal structure of the situation, whereas the imperfective looks at the situation from inside, and as such is crucially concerned with the internal structure of the situation".

(Comrie 1976: 3-4)

It becomes immediately evident that aspect has in fact nothing to do with the actual internal temporal constituency of the situation. It depends on the vantage point (to anachronistically use a cognitive term, since this is essentially a cognitive definition) adopted by the speaker.

The independence of aspect from the real temporal constituency of the situation becomes even more obvious when it is further stressed, with plenty of examples, that the perfective does not express punctuality, brevity or boundedness, nor the imperfective duration or non-boundedness (Comrie 1976: 16-40); these may arise as implicatures but as such are cancellable by the context.

The important thing about aspect is that speakers have a CHOICE: they can select their vantage point, within or without the event. The result is that the two aspects are interchangeable: the same event can be described in two different ways, in grammatically acceptable sentences. Comrie's own examples from Greek and French (1976:17) are shown in (3) and (4):

(3) ebasíleue déka étē - il régnait trente ans

(4) ebasíleuse déka étē - il régna trente ans

The choice depends on a number of factors, including the implicatures arising from the adoption of different vantage points: the imperfective is more likely to be used when the speaker wishes to stress the duration or the tediousness of an event and the perfective when the speaker emphasizes its completion; none of this, however, is compulsory. Both of the following sentences would be acceptable with either aspect, although interestingly a perfective (5) would be rather awkward, even though it refers to a completed event (the reason being that the context leaves no doubt that the emphasis is on the length of the event):

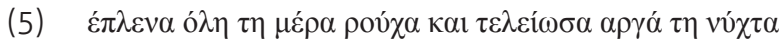

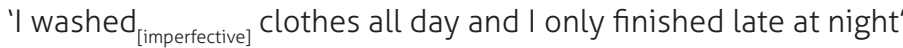

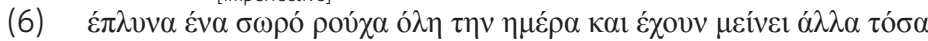
'I washed $_{\text {[perfective] }}$ a heap of clothes all day and there are as many left'

It was this interchangeability that led to the distinction being defined on the basis of subjectivity: while Aktionsart as an inherent characteristic is objective, aspect is subjective in the sense that it involves choice. The notion of subjectivity will be discussed in section 4 of this paper, after a brief look at the objections to the postulation of two grammatical categories. 


\section{Objections to the Aspect - Aktionsart Distinction}

The aspect - Aktionsart continuum proposed here presupposes the existence of both these categories; this existence, however, has been seriously challenged. The objections come from opposite directions: Cognitive Linguistics and Formal Semantics.

Langacker (e.g. 1987/1991) argues against the distinctions on the basis of the fact that speakers always have a choice of vantage point and hence can construe any situation as durative or not, the 'objective' temporal constituency being irrelevant. It is proposed here that this is exactly the argument that lends support to the claim of a viable distinction. There seems to be no doubt that there are objective differences in situations such as the one mentioned above between searching and finding and, more crucially, that they are obvious to speakers; the fact that they can be construed in ways that allow them to be expressed by the same aspect is precisely what renders the category so interesting, especially if it can be shown that objective temporal constituency interferes with aspect in linguistically significant ways.

Verkuyl's $(1993,1999,2007)$ objections concern exactly this point: he does not deny the possibility of drawing the distinction, but claims that Aktionsart is a purely ontological category, with no bearing on language and therefore on Linguistics. However, there is evidence of systematic interaction between Aktionsart and aspect in language. There are few, if any, languages where aspect functions entirely independently of Aktionsart - even Greek, which is one of the freest in its use of aspect, is subject to a few Aktionsart restrictions. These concern the two more 'extreme' verb classes, achievements and states:

Achievements, as a result of their instantaneous nature, have some difficulty combining with the imperfective, since, in order for a situation to be seen as developing, some duration is necessary. Their imperfective forms are normally habitual, with one exception: when they are used as a background or backdrop to another event:

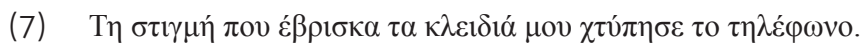

'The moment I found [-perfective] my keys, the phone rang".

They can also be used metonymically to refer to the process leading up to them, as in:

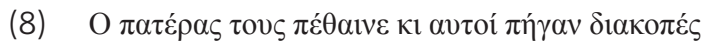

'Their father died ${ }_{[- \text {perfective] }}$ (was dying) and they went away on holiday'. 
On the other hand, states, which are open-ended and atelic, react in two ways to a combination with the perfective: it either presents them in a genuinely perfective manner, i.e. as a whole (9), or it singles out the point of entry into the state, as in (10):

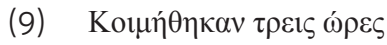

'they slept $\mathrm{f}_{\text {+perfective] }}$ for three hours'

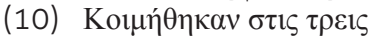

'they slept ${ }_{[+ \text {perfective] }}$ at three'

The Slavic languages are much more constrained by Aktionsart and English is entirely bound by it: there are serious lexical restrictions on the use of the progressive, dealt with in section 4 of this paper. Verkuyl (e.g. 1994: 15) deals with this by postulating two parameters, $[ \pm \mathrm{SOA}]$ and $[ \pm \mathrm{ADD} T \mathrm{TO}$. The former refers to the type of arguments in the sentence; the latter refers to the presence or absence of movement, both literal and metaphorical, from Source to Goal, i.e. to the distinction between events with and without phases, or situations involving change and stative situations (Verkuyl 1999: 23-24) and thus essentially to Aktionsart. In the next sections it will be proposed that the varying degrees to which Aktionsart interferes with aspect, thus limiting the speaker's freedom of choice, is what causes the gradience between the two categories.

\section{Aspect and Subjectivity}

\subsection{The Concept of Subjectivity}

The concept of subjectivity is the object of considerable controversy. It is one of the most popular subjects these days, mainly within the cognitive paradigm, and also in its historical dimension, i.e. as subjectivisation or subjectification, which features heavily in the literature on grammaticalization. ${ }^{9}$ The main concepts are those of Langacker $(1990,2006)$ and Traugott $(1995,2010)$, which differ considerably, despite their presentation as similar in most of the relevant literature.

9 See e.g. Langacker (1990), Nuyts (2001), De Smet, H. \& J.-C. Verstraete (2006) and Stein \& Wright (1995), Athanasiadou, Canakis \& Cornillie (2006), Davidse, Vandelanotte \& Cuyckens (2010) respectively. 
Langacker's concept is not related to the semantic content of the linguistic expression but to the viewing arrangement and the presence or absence of the speaker; maximal subjectivity is associated with the speaker functioning as a tacit conceptualizing presence.

For Traugott subjectivity involves the expression of self and the representation of a speaker's perspective or point of view in discourse.

Nuyts' (2001) concept is distinct from both, even though it is usually included in the Traugottian line of thought, to which it does bear greater affinity. He sees subjectivity as a subcategory of evidentiality, defining it not in the traditional terms of the quality of evidence, but rather in terms of whether the evidence is only available to the speaker or more widely known.

In this paper subjectivity is seen as a choice of expressing the same, truth-conditionally determined, meaning through different linguistic forms, specifically through different aspectual forms of the verb; this is a very broad conception of subjectivity, to the point perhaps of being thought of as vacuous, but nevertheless quite rigidly defined and at the same time conforming to the common meaning of subjectivity. ${ }^{10}$

\subsection{Problems With Choice and Subjectivity}

Even in this elementary sense of availability of choice, subjectivity as the basis for defining aspect and Aktionsart presents difficulties, which have been pointed out in the literature.

\subsubsection{Adverbials and Complements}

Almost every book or article on Greek aspect mentions the imposition of one

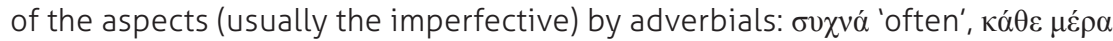

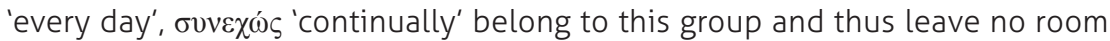
for choice. While this is true in a sense -these adverbials co-occur exclusively with the imperfective- it has to be taken into account that adverbials are themselves the result of choice on the part of the speaker. Outside the classroom there is no situation where a speaker is presented with an adverbial around which he or she has to build a sentence. The adverbials themselves, therefore, do not impose limitations to the speaker's choice and to subjectivity as understood here.

10 For fuller argumentation see Moser (forthcoming). 
Some matrix verbs, on the contrary, do impose restrictions on the choice of aspect in the complement. These fall mainly under three categories:

- 'aspectual' verbs: $\alpha \rho \chi i \zeta \omega$ 'start', $\sigma v v \varepsilon \chi i \zeta \omega$ 'continue', $\sigma \tau \alpha \mu \alpha \tau \alpha \dot{\alpha} \omega$ 'cease' etc. $\Rightarrow$ imperfective (exception: verbs meaning 'be about to' $\Rightarrow$ perfective)

- verbs of learning/possession of skills: '̌́s $\omega \omega$ 'know', $\mu \alpha \theta \alpha i v \omega$ 'learn' $\Rightarrow$ imperfective

- verbs of perception: $\beta \lambda \dot{\pi} \pi \omega$ 'see', $\alpha \kappa o v \omega \omega$ 'hear' with na-complements $\Rightarrow$ imperfective

It is easy to find ad hoc explanations: aspectual verbs explicitly refer to a point or time chunk of a process, while verbs of learning etc. refer to a permanent attribute; they still constitute an example of Aktionsart interfering with the choice of aspect. The case of verbs of perception is different: here the imperfective complement denotes the subject's direct sensory knowledge of the situation and therefore has to present the situation as ongoing. ${ }^{11}$

\subsubsection{Subjectivity, Habitual and Progressive}

Objections of a more theoretical nature to subjectivity as the defining property of aspect have also appeared in the literature. Interestingly, almost all of them concern the subdivisions of the imperfective aspect, which are represented in Figure 6:

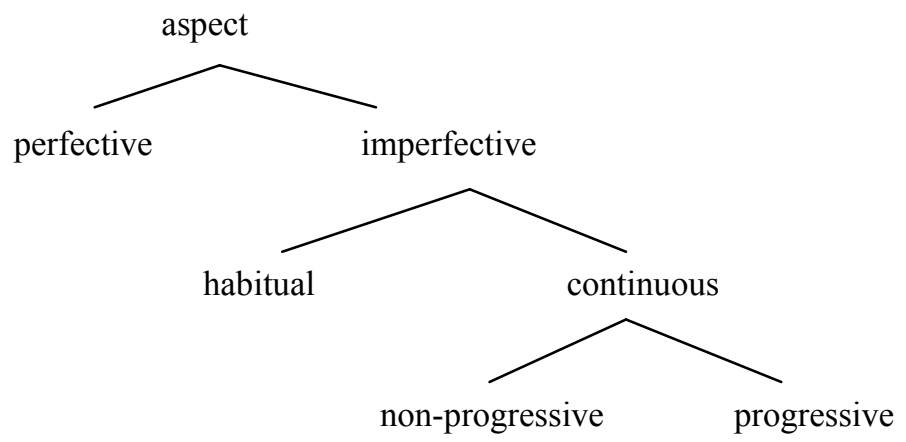

Figure 6. Aspect and its subdivisions according to Comrie 1976: 26

11 These constructions, then, seem to function as evidentials, suggesting interesting paths of research, not least on subjectivity in Nuyts' (2001) terms, with possible support for Nikiforidou's (2004) analysis associating the imperfective with subjectivity; cf. the detailed analyses by Delveroudi et al. (1993) and Veloudis (2001). It should be pointed out that these finite na-complements of verbs of perception, rather than being descendants of infinitival complements, have replaced an Ancient Greek evidential participial construction. 
Oddly enough, this categorization has remained unchallenged, in a field where everything else is under constant dispute; it will be shown here, however, that much of the dissent about aspect and its relationship to Aktionsart is caused precisely by these subdivisions of the imperfective.

As early as 1982, Bache challenged the subjectivity-based definition of aspect, demonstrating the unavailability of choice in the case of the progressive and even more so in that of the habitual. As will become evident from the following discussion, mainly on the basis of the Greek aspectual system, he is entirely right.

Greek expresses morphologically only the main [ \pm PERFECTIVE] opposition, although the habitual - continuous opposition has some syntactic consequences. The habitual is used in cases of regular repetition of events; as in other languages, simple repetition is not a sufficient condition ${ }^{12}$ for its use, as is shown by example (12); in fact simple repetition requires the perfective:

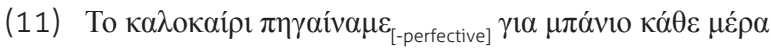
'in the summer we went (=used to go) swimming every day'

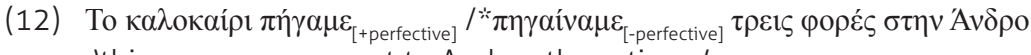
'this summer we went to Andros three times'

The most crucial fact about the Greek habitual from the point of view of this investigation is that it leaves no room for choice: not only is it impossible to use the imperfective for a non-habitually repeated situation, but a habitual situation can only be expressed by the imperfective.

The [ \pm PROGRESSIVE] opposition is irrelevant to Greek, though of course logically possible. It needs to be pointed out that the aspectual opposition of Greek is very different to that of English, where the non-progressive includes all other subdivisions. The [ \pm PROGRESSIVE] opposition is thus wrongly, though frequently, equated with the $[ \pm$ PERFECTIVE] one, with dire consequences for the theoretical analysis of aspect. Greek is also different to, say, Spanish, which expresses both oppositions. Languages which possess the progressive impose severe restrictions on its use: it is allowed only with verbs expressing situations consisting of discernible phases (activities and accomplishments):

12 According to Comrie (1976: 26-30) and on the basis of examples such as The temple of Diana used to stand at Ephesus repetition is not even a necessary condition; this, however, seems to be a case of an extension of the use of the habitual to a subset of (long-lasting) imperfective situations, in a language with no other means of distinguishing non-progressive imperfective situations from perfective ones. 
(13) Last night he walked home. All the way he was humming (a tune).

(14) He used to love walking, but he doesn't any more. While he "was loving it, he often walked home in the evenings.

(15) Last night I found / "was finding the pen I'd lost.

Uses of the progressive with states and achievements constitute a deliberate flouting of the rule, used to convey extra meaning:

(16) All those months that they stayed out of touch their father was dying.

(17) They were so arrogant about their skills and now they're losing the game. I'm loving this!

Bache is therefore entirely justified with respect to the unavailability of choice and therefore absence of subjectivity in the case of the habitual and the progressive; rather than changing the definition of aspect, however, I opt for the rearrangement of the categories involved along a continuum of subjectivity.

\section{The Aspect - Aktionsart Continuum}

A gradient of subjectivity accommodates all the facts pointed out so far:

- the fact that free choice is not an attribute of all types of aspect

- the fact that there are different degrees of freedom of choice within and across languages, for instance

- that habituality in Greek leaves no room for choice

- that it does in English, though only for the past tense

- that progressivity in English is a matter of choice, but this choice is limited to certain types of Aktionsart

According to the discussion in section 1 , the two ends of the continuum are rigidly defined in terms of subjectivity: Aktionsart is objective and aspect is subjective. The only aspectual category that can be accommodated at the subjective end of the continuum is [ \pm PERFECTIVE]. The English [ \pm PROGRESSIVE] would be closer to the aspect end, since it is optional, but dependent on Aktionsart. A fully-fledged [ \pm HABITUAL], such as that of Greek, which is determined by objective characteristics of the situation, would be very close to the Aktionsart end, though not coinciding with it for two reasons: (a) that habituality is not inherent in the meaning of verbs and (b) that crosslinguistically habituality is very frequently expressed by the imperfective, although there exist languages with exclusively habitual forms. A habitual 
such as the English used-to construction, with its optionality combined with the possibility of being used as a continuous, would be closer to the aspect end. ${ }^{13}$

The continuum, taking into account the categories considered so far, would have an appearance like the one presented in Figure 7 :

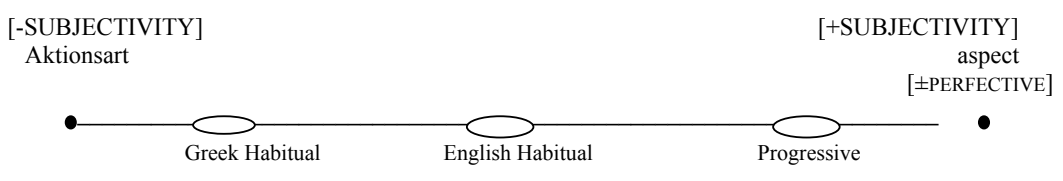

Figure 7. The Aktionsart-aspect continuum

So far, the discussion has been limited to subjectivity, the feature that differentiates aspect and Aktionsart, as well as the various subdivisions of the former, creating the gradient. There has been no mention of (a) feature(s) that unite(s) the two categories. The notion of a continuum in fact presupposes the existence of a common property or properties.

It has been seen above (section 2.2.2) that the common property cannot be internal temporal constituency, since the basic aspectual distinction [ \pm PERFECTIVE] is independent from the actual temporal constituency of each situation. At the same time, the interaction of [ \pm PERFECTIVE] and Aktionsart outlined in section 3 suggests that there is some affinity between the imperfective and atelic situations on the one hand and between the perfective and telic situations on the other, in the sense that the members of each pair combine in a more straightforward manner, without any sideeffects. It was proposed in Moser (1994) and elaborated in Moser (2009) that what comes into play is a feature of telicity. Telicity here is taken at its most abstract, with a different realization in each of the categories. The telicity involved in Aktionsart is based on reality: Vendler's accomplishments and achievements both include a real end point in their meaning, whether this end point is realized in actual fact or not; they are terminative. As can be seen in Table 1, accomplishments are actually activity verbs with a complement which signals exactly this end point. Aspectual telicity, on the other hand, which is embodied in perfectivity, is completely notional. It is the logical result of viewing a situation as a whole: this is impossible unless some kind

13 The high frequency of imperfectives used as habituals is not difficult to explain. The temporal structure of an event that consists of a series of clearly discernible phases (such as an activity or accomplishment) is very similar to that of a series of independent events perceived as a set. This is also what allows for the reverse shift in the case of the English habitual. 
of boundary is visualized in order to keep the situation in question distinct from its surroundings.

While the perfective brings along a boundary, however abstract, the imperfective does not preclude it; it simply does not require it and does not pay any heed to its presence or absence. The logical requirement for the imperfective aspect is of a different kind: in order for the internal constituency of a situation to be brought to the fore, there has to be an internal constituency. This does not mean that the situation has to consist of discernible phases (this widespread idea is the result of analyses based on languages that do not have the opposition [ \pm PERFECTIVE], but only [ \pm PROGRESSIVE], such as English); it simply needs to have some duration, i.e. not to be punctual. This is why achievements have some difficulty in combining with the imperfective. However, since telicity and atelicity are entirely abstract in the case of aspect, these problems can be and are indeed overcome in the way that was demonstrated in section 3 (examples 7 and 8 ).

Another way of formulating the outcome of this last discussion, which is presented schematically in Table 3, would be to say that telicity (and its absence) is objective in the case of Aktionsart and subjective in the case of aspect.

Table 3.

Telicity, aspect and Aktionsart.

\begin{tabular}{|c|c|c|}
\hline & +TELICITY & - TELICITY \\
\hline \multirow{2}{*}{ 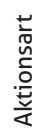 } & accomplishments & activities \\
\hline & achievements & states \\
\hline 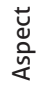 & perfective & imperfective \\
\hline
\end{tabular}

It follows from the analysis that, in terms of subsective gradience, the prototypical aspectual category is [ \pm PERFECTIVE], being the only aspectual opposition that allows for entirely free choice and therefore the only entirely subjective category in the sense of subjectivity defined above.

An interesting aspect of the Aktionsart-aspect continuum, which goes beyond the topic of this paper, is the possibility of applying it to the historical development of the category aspect in Greek, as well as to comparative studies of aspectual systems. 


\section{Conclusion}

The analysis of the relationship between aspect and Aktionsart has led to the following conclusions:

- aspect and Aktionsart are related but distinct categories

- they are related through telicity (abstract in the case of aspect and concrete in the case of Aktionsart)

- they are differentiated through subjectivity, in the sense that Aktionsart refers to the objective temporal structure of situations, while aspect is independent of it and therefore is a matter of choice

- while Aktionsart has an ontological basis, it is linguistically significant, since it interacts with aspect semantically and syntactically

- the two categories form a continuum of subjectivity in the sense outlined above, with Aktionsart at the objective and (prototypical) aspect at the subjective end

- the prototypical aspectual category is the perfective-imperfective opposition [ \pm PERFECTIVE], while the categories that have become known as subdivisions of the imperfective are in fact intermediate categories on the aspect-Aktionsart continuum.

As an instance of intersective gradience, it is hoped that the aspect-Aktionsart continuum proposed in this paper has lent some support to the claim that gradience, far from being based on vague concepts, requires rigid definitions of focal categories in the case of subsective gradience and the categories at the two ends of the continuum in the case of intersective gradience. 


\section{References}

Aarts, B. 2007. Syntactic Gradience: the Nature of Grammatical Indeterminacy. Oxford: Oxford University Press.

Aarts, B., D. Denison, E. Keizer and G. Popova (eds.) 2004. Fuzzy Grammar: A Reader. Oxford: Oxford University Press.

Athanasiadou, A., C. Canakis and B. Cornillie (eds.) 2006. Subjectification: Various Paths to Subjectivity. Berlin/New York: Mouton de Gruyter.

Bache, C. 1982. Aspect and Aktionsart: towards a semantic distinction. Journal of Linguistics 18: 57-82.

Bella, S. 2005. Cognitive motivation and pragmatic function of the Greek deictics. Journal of Greek Linguistics 6: 39-60.

Bolinger, D. 1961. Generality, Gradience and the All-or-none. The Hague: Mouton.

Bybee, J., R. Perkins and W. Pagliuca. 1994. The Evolution of Grammar: Tense, Aspect and Modality in the Languages of the World. Chicago/London: The University of Chicago Press.

Clairis, C. and G. Babiniotis, in collaboration with A. Moser, A. Bakakou-Orfanou and S. Skopeteas. 2005. Gramatiki tis Neas Elinikis, Domoliturgiki-Epikinoniaki [Modern Greek Grammar]. Athens: Ellinika Grammata.

Comrie, B. 1976. Aspect. Cambridge: Cambridge University Press.

Comrie, B. 1985. Tense. Cambridge: Cambridge University Press.

Davidse, K., L. Vandelanotte and H. Cuyckens (eds.) 2010. Subjectification, Intersubjectification and Grammaticalization. Berlin/New York: Mouton de Gruyter. 
Delveroudi, R., I. Tsamadou and S. Vassilaki. 1993. Contribution à l'étude de la modalité en grec moderne: le marqueur va. Collection ERA 642. Paris: UFRL, Laboratoire de linguistique formelle (URA 1028).

De Smet, H. and J.-C. Verstraete. 2006. Coming to terms with subjectivity. Cognitive Linguistics 17: 365-392.

Holton, D., P. Mackridge and I. Philippaki-Warburton. 1997. Greek Grammar: A Comprehensive Grammar of the Modern Language. London: Routledge.

Hopper, P.J. and S. Thompson. 1984. The discourse basis for lexical categories in Universal Grammar. Language 60: 703-752.

Jaszczolt, K. 2007. Representing Time: An Essay on Temporality and Modality. Oxford: Oxford University Press.

Langacker, R.W. 1987/1991. Foundations of Cognitive Grammar. Volumes I and II. Stanford: Stanford University Press.

Langacker, R.W. 1990. Subjectification. Cognitive Linguistics 1: 5-38.

Moser, A. 1988. The History of the Perfect Periphrases in Greek. Doctoral dissertation, University of Cambridge.

Moser, A. 1994. Pion ke apopsis tou rimatos [Ationsart and Aspect in Greek]. Parousia Monograph n. 30. Athens: National and Kapodistrian University of Athens.

Moser, A. 2009. Apopsi ke xronos stin istoria tis Ellinikis [Aspect and Tense in the History of Greek]. Parousia Monograph n. 77. Athens: National and Kapodistrian University of Athens.

Moser, A. forthcoming. From Aktionsart to aspect: grammaticalization and subjectification in Greek.

Nikiforidou, K. 2004. Grammatical Meaning and Construal: A Cognitive Linguistic Approach. Parousia Monograph n. 61. Athens: National and Kapodistrian University of Athens.

Nuyts, J. 2001. Subjectivity as an evidential dimension in epistemic modal expressions. Journal of Pragmatics 33: 383-400.

Rosch, E. 1973. Natural categories. Cognitive Psychology 4: 328-350. 
Rosch, E. 1978. Principles of categorization. In E. Rosch and B.B. Lloyd (eds.), Cognition and Categorization. Hillsdale, N]: Erlbaum, 27-48. Reprinted in Aarts et al. (2004), 91-108.

Sasse, H.-J. 1991. Aspekttheorie. In H.-J. Sasse (ed.) Aspektsysteme. Arbeitspapier n. 14. Köln: Institut für Sprachwissenschaft, Universität zu Köln, 1-35.

Stein, D. and S. Wright. 1995. Subjectivity and Subjectivisation: Linguistic Perspectives. Cambridge: Cambridge University Press.

Taylor, J.R. 1989. Linguistic Categorization: Prototypes in Linguistic Theory. Oxford: Clarendon Press.

Traugott, E.C. 1995. Subjectification in grammaticalization. In D. Stein and S. Wright (eds.), Subjectivity and Subjectivisation: Linguistic Perspectives. Cambridge: Cambridge University Press, 31-54.

Tsangalidis, A. 1999. Will and Tha: A Comparative Study of the Category Future. Thessaloniki: University Studio Press.

Tsangalidis, A. 2010. (Inter)subjectivity and (inter)subjectification: A reassessment. In K. Davidse, L. Vandelanotte and H. Cuyckens (eds.), Subjectification, Intersubjectification and Grammaticalization. Berlin/New York: Mouton de Gruyter, 29-71.

Tsohatzidis, S. (ed.) 1991. Meanings and Prototypes: Studies in Linguistic Categorization. London/ New York: Routledge.

Veloudis, I. 2001. Ná kai na [Ná and na]. Eliniki Glosologia '99: Praktika tu 44 Diethnus Sinedriu Elinikis Glosologias [Greek Linguistics '99: Proceedings of the 4th International Conference on Greek Linguistics]. Thessaloniki: University Studio Press, 243-250.

Vendler, Z. 1957. Verbs and Times. The Philosophical Review LXVI: 143-160. Reproduced in Z. Vendler, 1967, Linguistics in Philosophy, Ithaca: Cornell University Press, 97-121.

Xydopoulos, G. and A. Tsangalidis. 2007. I rimatiki apopsi stin eliniki ke i sxesis $E_{\text {, }}$ R, S [Verbal aspect in Greek and the relations E, R, S]. Studies in Greek Linguistics 27 (In memory of A.-Ph. Christidis): 322-336. 